\title{
Optimizing Strategies of Modern Construction Drawing Design
}

\author{
Peng Yun \\ Yunnan Technology and Business University, Yunnan, China, 651701
}

Keywords: Modern; construction drawings; design; optimization

\begin{abstract}
The rapid development of market economy in today's society promotes the rapid upgrading of China's construction industry. In order to adapt to the development speed of the new era, all links of construction engineering must be strictly controlled. As the construction foundation of construction engineering, construction drawing design plays a role in controlling project cost, determining project quality and at the same time guiding the whole construction process. The construction scheme of one link has the function of deepening and perfecting. Therefore, it has positive practical significance to discuss the optimization of construction drawing design.
\end{abstract}

With the improvement of people's quality of life year by year, people's requirements for living environment level are gradually improved, so the technical requirements for architectural designers are also increasingly high. As a construction drawings designer, not only the level of technical knowledge should be too hard, but also the construction materials and crafts should be understood. Therefore, it is necessary for designers to have sufficient design concepts and knowledge reserve, taking into account all-round factors, so as to achieve the maximum rational allocation of design space.

\section{Main problems in the design of construction drawings}

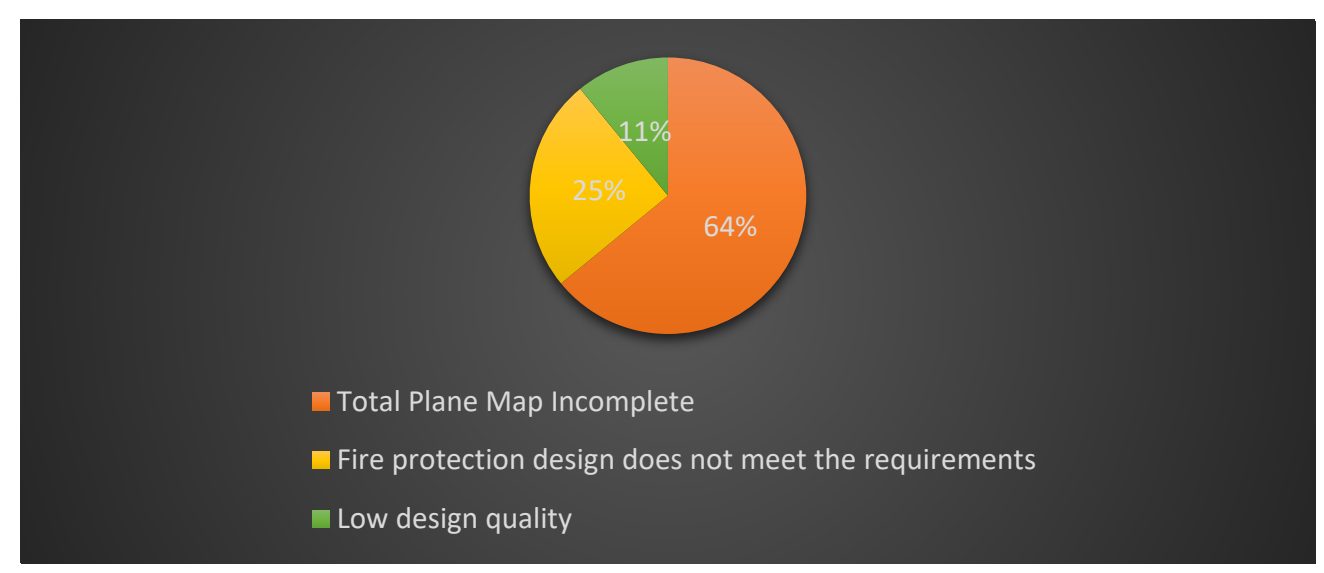

Figure1 Main problems in the design of construction drawings

As shown in Figure 1, a detailed analysis is presented below.

\subsection{Total plane map incomplete}

During the construction of the project, some small-scale construction projects will have the situation that the design depth of the general plan does not meet the standard. In the process of designing construction drawings, designers usually only locate the architectural plane, pay too much attention to the architectural plane design, and neglect other elements in the process of architectural design, such as the design of spacing and gradient and slope direction, in addition, there is a lack of corresponding warning signs. The above problems will affect the construction efficiency of construction projects.

\subsection{Fire protection design does not meet the requirements}

In the process of designing construction drawings, usually because the setting of road turning 
radius does not meet the requirements of the code, the design of fire fighting sites does not meet the standard, which leads to the problem of hidden safety hazards in fire protection design. In addition, some high-rise buildings in the design, there will be no reserved deformation joints and reserved narrow deformation joints, which will lead to the building in the use of cracks in the process, leading to fire protection design can not achieve results.

\subsection{Low design quality}

At present, in order to win the project, some construction enterprises do not pay attention to the quality of construction drawings. Because of the insufficient design cycle, some important problems are ignored in the first stage of construction drawings design, which seriously affects the quality of construction drawings. Therefore, construction enterprises must recognize the seriousness of the problem, and speed up the drawing speed to ensure that the quality of construction drawings meets the relevant standards, thereby improving the construction progress of the project.

\section{The Function of Optimizing Construction Design Drawings}

\subsection{Is beneficial to the control of construction cost and material saving}

Construction drawings have a great impact on construction costs. If the construction company optimizes the internal design of construction drawings, and formulates the maximum limit of design, then teaches the design drawings to professional people for analysis and management, it can play the most professional budget control effect. Company managers need to understand the project according to the management drawings, integrate the higher cost but can be improved, and ultimately ensure that the total cost of the project can be controlled in a reasonable cost.

Because of the rapid development of the construction industry, many designers believe that as long as the most classic design drawings are copied, a building can be built. This will lead to them not attaching importance to the design and optimization of construction drawings, and not considering the design quota according to the actual situation, and ultimately unable to achieve the purpose of cost control. Designers need to optimize the process of building drawings are mainly divided into the following points: first, designers need to hand over carefully designed drawings to the construction company, the company assigns professionals to carry out scientific and detailed accounting of construction costs, calculate budget costs and economic standards in the construction process and budget control costs within the company, all aspects. In order to ensure that the cost is optimized, the design drawings are checked in bits.

Secondly, construction companies need to find experts to calculate the cost of key and difficult points in the design, and then communicate fully between designers and experts on the same issues to ensure that the design drawings can be optimized and adjusted. Ultimately, construction companies need to hold special meetings to optimize the design drawings that need to be optimized, and formulate a set of appropriate schemes for improvement, so as to ensure that construction companies can achieve the goal of cost control through the design drawings.

\subsection{Increasing the utilization ability and accuracy of buildings}

At the present stage of rapid development of real estate, the construction industry is also accelerating its development. The previous consumption concept has not adapted to the current consumption demand. Consumers have put forward better requirements for construction and residence. They have put forward higher requirements for the utilization of space in buildings, the design of structures and the quality of buildings. However, designers in current architectural design pay more attention to structures. It ignores the design of other aspects, so other aspects need to be considered in the design, and ultimately increase the utilization capacity and accuracy of the building.

For the situation that architectural drawings are biased towards structural design in construction, designers can locate the design of architectural drawings before design. First, they can communicate with the builders whether the positioning of the building is high-end or ordinary, what kind of 
building is it, then design according to the positioning, and carefully design the common public buildings in design. Designers need to use design drawings to ensure that consumers can better position the building when they see the building, so that design drawings can increase the utilization ability and accuracy of the building, and increase the recognition rate of consumers for the building function.

\subsection{No complex construction process}

The construction drawings in the construction process are only designed according to the designer's drawings. There are many problems when they are really used in the construction. However, the designer only designs according to the plane of the building, lacking the common sense and experience of on-site construction. In the imagination and Inspiration of the designer for the building, the actual situation of the construction site is not really taken into account, and then there is no real implementation. Workers understand, which will lead to designers do not understand the actual situation, and ultimately lead to the construction drawings are not practical.

\section{Optimum Design Strategy of Construction Drawings}

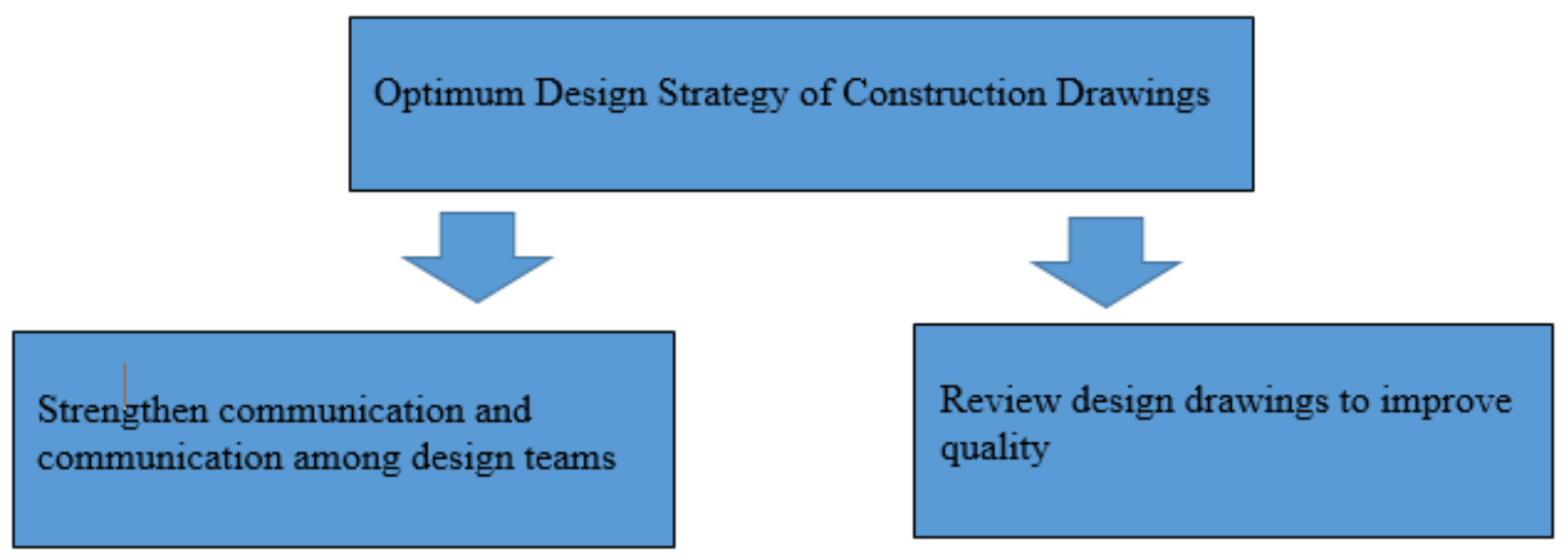

Figure 2 Optimum Design Strategy of Construction Drawings

As shown in Figure 2, a detailed analysis is presented below.

\subsection{Strengthen communication and communication among design teams}

By strengthening the information communication and technical exchange among the members of the design team, we can ensure the full cooperation and cooperation among the designers. And in view of the experience and technology exchange and summary, achieve complementary advantages, and jointly improve the overall design quality of construction projects. Therefore, it requires designers to establish a correct concept of cooperation and actively promote their professional knowledge and professional accomplishment. At the same time, in the process of design, we can not ignore the objective requirements of novelty, design in full accordance with the overall project requirements, strengthen the division of labor and cooperation between the various links, do a good job of information convergence, to avoid deviations in design.

\subsection{Review design drawings to improve quality}

The review of construction drawings can discover the design errors and defects in the construction drawings in time, so as to effectively improve the design quality. Moreover, due to the shortcomings of the designer's own professional accomplishment and practical experience, it is easy to have problems and defects in the process of construction drawings design. Therefore, strict review of construction drawings is carried out to improve the quality of construction drawings, and to avoid the gap between construction drawings and the actual construction situation, so as to reduce the probability of construction quality problems.

As an important reference basis for construction work, the quality of construction drawings must 
be guaranteed. For example, in the construction drawings, besides marking the basic overall structural dimensions of the building frame, the height of fire doors in the underground garage must be refined; in the case of large-scale drawings, different fire protection zones must be marked, and the details between stairs or elevators should be partitioned in detail, so as to effectively improve the construction drawings.

\section{Conclusion}

The importance of construction drawings is self-evident, but there are still many problems in different degrees. This article combines the importance of construction drawings and optimization design strategy to analyze, so as to actively and effectively find the problems in construction drawings, and put forward targeted solutions. Through the optimization of construction drawings, it can also greatly promote the overall quality and level of construction projects, reduce construction costs, and provide important reference for later maintenance.

\section{References}

[1] Bu Jabbing. Design problems and Countermeasures of construction drawings for construction engineering structures [J]. Engineering Technology Research, 2017, (1): $222+228$.

[2] Li Chang. Brief discussion on the new business development of engineering consulting industry - Optimization of construction drawing design [J]. China Residential Facilities, 2017, (7): 126-128.

[3] Yang Dan. On the Optimal Measures for the Design of Construction Drawings [J]. Decoration and Decoration World, 2018 (7): 146.

[4] Chen Die. On the Optimizing Measures of Construction Drawing Design [J]. Building Materials and Decoration, 2016 (24): 75-76.

[5] H Songhua. Talking about Key Points Analysis and Research of Architectural Construction Drawing Design [J]. Architectural Engineering Technology and Design, 2015 (11): 278. 